Journal of English Language Teaching and Applied Linguistics

ISSN: 2707-756X

DOI: $10.32996 /$ jeltal

Journal Homepage: www.al-kindipublisher.com/index.php/jeltal

\title{
Effects of Activating Background Knowledge in Listening Skill and How to Improve IELTS Listening
}

\author{
Nguyen Nu Nhu Linh 8 (D) \\ Saigon University, Ho Chi Minh City, Vietnam
}

$\triangle$ Corresponding Author: Nguyen Nu Nhu Linh, E-mail: nguyennu_nhulinh@yahoo.com

\begin{tabular}{|c|c|}
\hline ARTICLE INFORMATION & ABSTRACT \\
\hline $\begin{array}{l}\text { Received: May 02, } 2021 \\
\text { Accepted: June 08, } 2021 \\
\text { Volume: } 3 \\
\text { Issue: } 6 \\
\text { DOI: } 10.32996 / \text { jeltal.2021.3.6.3 }\end{array}$ & $\begin{array}{l}\text { Among the well-known international English tests, IELTS has been seen as one of the } \\
\text { most well-trusted and popular to EFL learners throughout the world. In Vietnam, most } \\
\text { of the universities require their EFL students to have an IELTS score of } 6.5 \text { or } 7.0 \text { to } \\
\text { fulfil their bachelor degree program, which is not quite an easy job. The paper } \\
\text { emphasizes the role of background knowledge in improving IELTS Listening scores for } \\
\text { EFL students at Saigon University. The research was done by observing two groups of }\end{array}$ \\
\hline $\begin{array}{l}\text { Background knowledge, IELTS } \\
\text { Listening, Listening } \\
\text { comprehension }\end{array}$ & $\begin{array}{l}\text { students learning Listening Module } 3 \text { at the institution. They were required to do the } \\
\text { same test; however, while a group was constructed with pre-listening activities, the } \\
\text { other simply listened and completed the task without preparation. The result showed } \\
\text { little difference between the two groups in terms of efficiency, but most of the } \\
\text { students in the first group were able to complete their test in the first time listening } \\
\text { while some members of the latter group needed a second time. They were then } \\
\text { required to complete a survey, including learning styles and attitudes. The results also } \\
\text { tell us that EFL students pay much attention to pre-listening activities, and they } \\
\text { believe such tasks can help them do their listening test better. }\end{array}$ \\
\hline
\end{tabular}

\section{Introduction}

The International English Language Testing System, or IELTS is an international standardized test of English language proficiency for non-native English language speakers established in 1989 (Wikipedia). IELTS has been one of the most popular tests required by many educational institutes in the world in recent years. EFL students need it to study abroad, graduate from a university, pursue higher education, or have a good job. Therefore, improving IELTS scores is one of the targets of EFL learners in recent decades.

IELTS masters all four skills of English, including listening, speaking, reading and writing. Among the skills, listening seems to be essential but complex. According to Brown (2006), listening performance is the process of transmitting from auditory signals to the ear and brain. When people communicate with others, listening takes the largest proportion of $45 \%$, while speaking, reading, and writing can only respectively be in charge of 30\%, 16\% and 9\% (Young, 1999). In line with that, Liu (2008) states that mastering listening comprehension can be the first step to fully acquire the English language. Therefore, many researchers have been working on how to help students improve their listening results by focusing on tactics and techniques or trying to figure out difficulties that learners might have when doing listening tasks. Many of them believe that preparing activities in prelistening plays a big role in deciding the effectiveness of listening comprehension. Underwood (1989) argues that learners should be guided to understand the topic they are going to listen to rather than being plunged straight into listening tasks without any preparation because they lack chances to approach spoken language in the EFL context. He notes that such "preparatory work" helps learners have proper strategies to deal with listening texts.

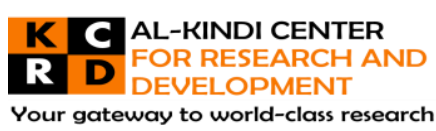

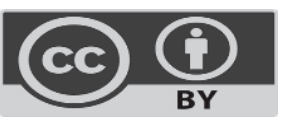

Published by Al-Kindi Center for Research and Development, United Kingdom. Copyright (c) the author(s). This open access article is distributed under a Creative Commons Attribution (CC-BY) 4.0 license 
IELTS listening is a test that covers academic and non-academic topics that might be unfamiliar to test-takers. In mastering the skill in EFL classroom, students should be supported with pre-listening activities to activate their background knowledge on the topic they will listen to, especially unfamiliar ones. The paper is investigating in positive aspects of activating prior knowledge in developing listening comprehension. The paper especially focuses on the effectiveness of such pre-listening activity on the IELTS listening test to help improve SGU EFL students.

\subsection{Research questions}

This research paper aims to answer the following questions:

1. To what extent is background knowledge important to students' listening ability?

2. How can teachers activate students' background knowledge to help them improve the IELTS listening performance?

\subsection{Significance}

IELTS is an important certificate that is very popular in education institutions in Vietnam. The test shows the strong collaboration of skills and knowledge of test-takers in both academic and non-academic topics.

Listening comprehension is an important skill to measure students' language proficiency. However, a lot of pre-listening activities are neglected for many reasons. One of them is teachers who underestimate the role of these activities in developing students' analytical ability or simply want to save time. Another reason could be from learners because they know very little about the topic they will listen to or do not understand the role of this step in listening comprehension results.

IELTS is especially vital to EFL students at some Universities in Ho Chi Minh City because it is one of the basic requirements for them to get their Bachelor Degree. In order to get IELTS 6.5 or 7.0, they not only practise all four skills properly but also accumulate good knowledge of every topic that IELTS might tests, without which test-takers cannot get high scores. Therefore, getting to know about EFL students' attitude and habit of developing background information is vitally important.

\subsection{Aim of the study}

The paper aims to raise awareness of EFL learners of background knowledge and pre-listening activities in improving listening comprehension. To that extent, this can help them build the habit of analyzing the information they know about a topic before doing a task either while learning in class or self-study at home, by all means in order to improve IELTS listening scores.

\section{Literature Review}

\subsection{Listening theory}

\subsection{Listening definition}

It is not easy to have an exact definition of listening. Researchers have had lots of ways to define it. Brown \& Yule (1983) believes that listening is an active activity that involves speakers, listeners, content and supporting elements such as images or diagrams. Many researchers have found that listening is the process of decoding the messages or signals, relating what people hear and what they already know (Rost, 2002). According to Devito (1995), listening has a process of receiving a message, understanding and evaluating it through communication. All factors such as voice, tone, sentence structures, and social contexts create a complex process in mastering the skill.

It is also true that listening is a difficult skill that challenges lots of EFL learners. According to Rost (2002), listening skills require "physiological and cognitive processes" at different levels. Swaffar \& Bacon (1993) adds that listening also involves listeners' attention to contextual and "socially coded acoustic clues"

Researchers have also investigated the problems that language learners face while listening. Underwood (1989) figures out several difficulties such as speech rate or lack of vocabulary; Goff (1999) emphasizes the role of concentrating, or Kurita (2012) focuses on listening anxiety.

In general, listening is a very complicated process that requires the collaboration of other factors. Listeners must understand the meaning of listening comprehension and its importance in mastering English.

\section{1.2. Theory of IELTS Listening}

IELTS - International English language testing system - is a testing program that assesses test takers' language proficiency who aim to study or work in an English-speaking country (IELTS 10, 2015). The test includes 4 skills: speaking, reading, listening and writing. IELTS listening has four sections. The first two parts cover social issues while the rest of them question academic 
knowledge. Totally, listeners have 30 minutes to listen and comprehend 40 items varied in types, such as: Multiple-choice items, Short-answer questions, Sentence completion, Note/summary/flow chart/table completion items, Labeling a diagram/plan/map, Classification items, and Matching items.

Of all IELTS four skills, listening is considered to be the most challenging and least predictable part of preparing before the test. In fact, either in Speaking, Reading, or Writing, test-takers can easily find similar tests, topics or question types to practice. However, it is not the same for listening, whose topics and questions vary a lot. Therefore, Badger, Yan, X. (2009) claims that listening can be considered the main challenge for test-takers. Field, J. (2009) especially focuses on Section 4 as "the most complex and complicated to do". Moreover, the one-time playing of the audio contributes to the difficulties that learners would encounter in the test.

\subsubsection{Role of teaching methods in listening comprehension}

Among 4 English skills, listening seems to be the most challenging to EFL teachers, as it requires a lot of time and practice which are totally limited in university education. While it is simpler to teach EFL students with given assignments and feedback, teachers usually find it hard to tell their students to listen and complete a task without specific techniques such as recognizing keywords, key phrases, main clauses, or sentences. Other difficulties like speech rate, accents or stress are also obstacles for selfstudy. One of the most important strategies is predicting and this is the role of instructors to help learners have the ability to guess words, ideas or structures of the required information. This is also the key to a good teaching method.

According to Arif (2016), Task-Based Language Teaching (TBLT) is one of the most suitable methods in teaching listening. There are 3 basic stages in this method: pre-tasks, task cycle, and post-tasks. In pre-tasks, teachers introduce the topic, listening aims via pictures, videos or games. Teachers can also use similar listening audios to make learners feel comfortable and relaxed. Nunan (2004) believes that this kind of activities can avoid students' hesitation to learn English.

\subsection{Theory of Background knowledge or Prior knowledge}

Longman dictionary of language teaching \& applied linguistics (Jack C. Richards \& Richard Schmidt) defines prior knowledge as

"what a learner already knows and which is available before a certain learning task, such as knowledge of vocabulary, syntax, the first language, or background knowledge about a topic or event".

In that way, Stevens (1980) and Marzano (2004) simply confirms that background knowledge is all about the content that a person already knows. It could be short but accurate and convincing.

On the other hand, many researchers have tried to find out more about prior or background knowledge in a much more complicated manner. Dochy and Alexander (1995) claim that it is the whole of a person's knowledge, including explicit and tacit knowledge, metacognitive and conceptual knowledge. Also, according to Biemans and Simons (1996), "new knowledge" is created when learners enter "a learning environment" with relevant things that they know. Learners' existing knowledge will be used to make inferences regarding the relationships and connections between ideas they learn from the text and conclude some new concepts and information implied in the text.

\subsection{Schema theory and effect of background knowledge on Listening comprehension}

According to Wikipedia, a schema "describes a pattern of thought or behavior that organizes categories of information and the relationships among them". People use schemata to organize available knowledge and convey future understanding.

Bartlett (1932) defines schema as "an active organization of past reactions or experiences". Schema theory is therefore important in language training. Rea and Mercuri (2006) explained that "A schema is the mental framework by which we organize concepts...Teachers encourage schema building...by helping students build background knowledge... access the background knowledge... and use it as a bridge to new learning" (p.47).

According to Richards \& Schmidt (2010), while people activate schemata in comprehension language, they access and interpret new experiences more quickly and efficiently. In line with that, Carrell \& Eisterhold (1983) confirm that activation of appropriate schemata during the message processing will be essential for efficient comprehension. 


\subsection{Methods to activate background knowledge in pre-listening activities}

Teachers can activate students' background knowledge in a number of ways.

\subsubsection{Questioning}

Questioning is a strategy that helps the learners clarify and comprehend what they will listen to. Ronald T. Hyman (1979) indicates that

"questioning is essential to teaching; both for the teacher and the student."

Donna Ogle (1986) developed the K-W-L strategy. In this strategy, the K stage (What you know) share the same role as the W (What you want to know) and the $L$ stage (What you learn). Students access the content of the listening text by listing what they already know about a certain topic, telling what they want to know about it, and finally summarising what they learn from it after listening and completing the task. Based on the strategy, students should be encouraged to express their ideas and knowledge in front of their teachers and classmates. However, some struggling learners rarely ask themselves or fail to ask themselves and therefore ignore them. In this case, Leslie Blair (2002) claims that teachers' wrong technique is often used. In her opinion, closedended questions from teachers do not promote the students in any way to demonstrate their level of knowledge or lack of knowledge. She believed that the quality of the questions decides the quality of a student's responses.

\subsubsection{Semantic mapping}

NSW Centre for Effective Reading defines Semantic mapping as

"a strategy for graphically representing concepts. A semantic word map allows students to conceptually explore their knowledge of a new word by mapping it with other related words or phrases similar in meaning to the new word."

Vocabulary is a vitally important foundation that any student needs to obtain. If the students understand a word, they can master the content of the text in a better way. Therefore, vocabulary is an unseparated aspect that develops background knowledge and is widely taught in every reading program (Beck, McKeown, McCaslin, and Burke; 1980). In fact, some research acknowledges that teaching vocabulary has the same power as building background knowledge (Marzano, 2004).

However, there is also some existing debates on teaching vocabulary among teachers. Some claim that focusing on specific words can lead to word-to-word translation, which is not encouraged in language teaching. Therefore, the way we teach students vocabulary is also a piece of cake. One of the strategies was once suggested by Paul Nation (1974). In his opinion, a good technique includes teaching the form of a word, then helping students connect forms and meanings. That way, students can guess the word without looking it up in a dictionary and develop their glossary. According to Hudson (1982) \& Johnson (1982), it is not a good idea to directly provide any single word but to equip learners with strategies necessary to expand their vocabulary. In addition, pre-teaching vocabulary probably requires that the words to be taught in semantically and topically related sets so that word meaning and background knowledge improve at the same time (Williams, 1987). Vocabulary and background knowledge obviously benefit each other. Zimmerman (1997) also shared the same idea to emphasize the role of vocabulary instruction focusing on semantic mapping as an acquisition strategy.

\subsubsection{Brainstorming}

This could be an easy activity that can be done individually, in pair, in a group or in the whole class to generate first ideas about a particular topic; after that, learners can discuss and evaluate the information each of them shares (Wolff, 1996). In fact, this kind of activity uses the schema theory mentioned above, using the knowledge learners know to refer to what they are going to learn. Therefore, whether brainstorming alone or combined with other activities, this strategy helps teachers evaluate their learners' schemata and are able to see the best of the students, reveal interests, encourage potentials and misconceptions to boost up their listening comprehension skills among them (Oxford, 1993).

\section{Methodology}

\subsection{Participants}

The participants of the research include EFL 44 students who studied Listening Module 3 in semester $12020-2021$ at Saigon University. They are all junior students who already finished Listening Module 1 and 2 in previous semesters. The participants were from two different classes but were instructed by the same teacher (also the author of the research). Both groups were required to complete a test but only one group were instructed with pre-listening activities; the other group did the test without any preparatory work. 
In order to help EFL students soon meet graduation requirements of IELTS 6.5, in the curriculum, students will have to learn each English skill in 3 Modules in 3 different semesters with 30 periods per each. Each Module provides necessary knowledge and techniques for IELTS. Therefore, the students at Module 3 all have certain English levels and have spent much time experiencing IELTS Listening. Specifically, they are quite familiar with IELTS Listening format, number of sections, number of speakers in each section, types of questions, types of topics in each section, and accumulated adequate vocabulary in various topics. However, it is unavoidable that their levels might be a bit different. To increase the credibility of the research, in the 15-week semester of research, the teacher decides to test them in week 12, after making sure they are instructed with the same techniques and knowledge in the same style.

Listening Module 3 guides EFL students with deep knowledge and IELTS listening techniques. The coursebook of this Module 3 is "Succeed in IELTS Listening" (by Andrew Betsis, Lisa Demiralp and Sean Haughton) which is equivalent to IELTS 6.5 - 7.0. According to the schedule, the students have to complete the first eight units of the book and the Listening Exam Guide part. The content of the book is rated by the group of teacher-in-charge as high level and will challenge the students a lot. In this Module, they are not only required to have proper listening skills and techniques to complete different types of tasks such as note completion, multiple-choice questions, chart/map completion, short answers, etc..., they also need a wide range of knowledge in both academic and non-academic fields such as History, Geography, Science, Arts, Real Estate, Work and Career, Economics, Finance \& Banking..., which are sometimes unfamiliar to them.

\subsection{Research design}

\subsubsection{Materials}

The research paper includes the following instruments:

(1) Observation and test results of two groups of participants who studied Listening Module 3 in semester $12020-2021$.

(2) Questionnaire: delivered and collected by the author in semester 1 2020-2021, after the participants finished their tests.

\subsubsection{Description of methodology}

Observation of the tests between two groups of participants and the test results

As mentioned earlier in the paper, the researcher decided to take her own classes-of-in-charge to observe and do the research. During the first 11 weeks of the semester, the students of the two groups were instructed with the same skills and techniques in the same teaching style, that is included a 3-step listening: pre-listening, while-listening and post-listening; among which half of the time was used to explain the topics, give vocabulary, guide difficult terms and provide proper techniques for each kind of questions and complete available pre-listening activity before doing the task. Basically, the students accumulated the same amount of knowledge from the teacher and performed a positive attitude towards the lessons.

In week 12, the participants were explained that they were doing a test to confirm the effectiveness of activating prior knowledge or pre-listening activities in tasks' results. The lesson chosen to observe and do tests is Task 2 of Unit 7 - "Research

Notes: Motivation in the Workplace" (Picture 1). This is an interesting topic about work and career which explains what motivates people to work. In an academic environment, the students might not know what could make a person work harder; however, among the basic needs that everybody had, they might think about what affected them to study well or work well in the future. That was the reason why the task was chosen.

One group was supported by such preparatory work while the other group is not. With pre-listening activities to help students memorize what they already knew about the topic before they actually listened, the teachers firstly raised a question: "What motivates you to work hard at school?", followed by "Why do people go to work?" "What can motivate them to work better?". After several minutes of discussion, the teacher guided the students to the note in Task 2 and explained that Maslow's Hierarchal Needs was divided into 5 levels as stated in the book, from basic to advanced. A few new words were also provided. 


\section{Research Notes: Motivation in the Workplace}

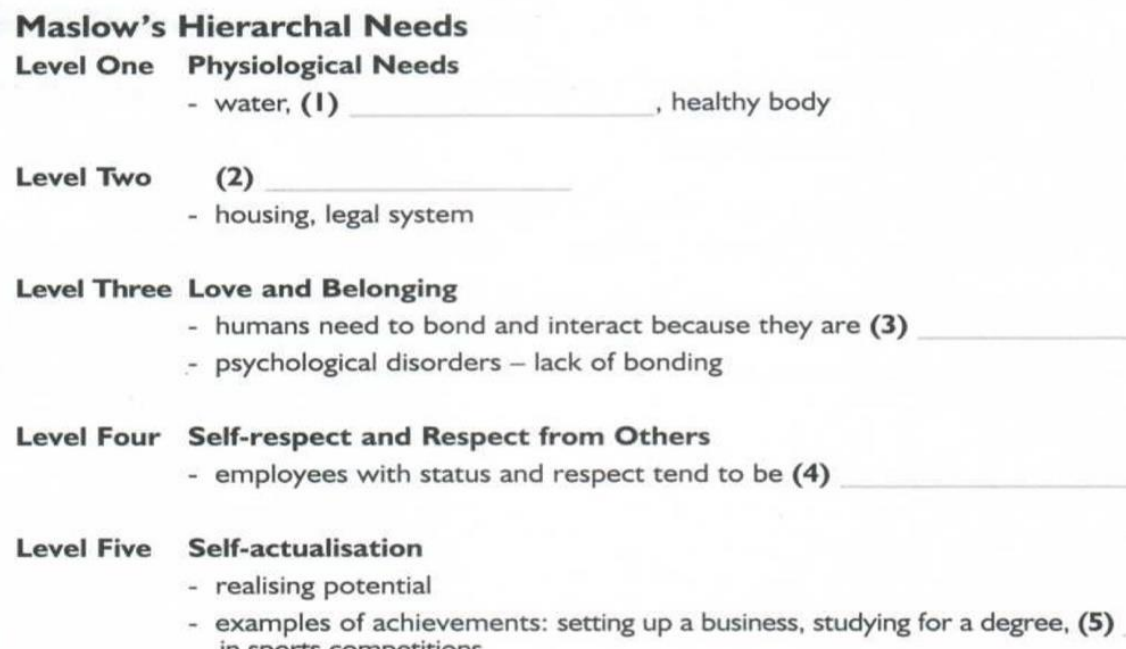

In general, in these kinds of "preparatory work", the students had interactions with teachers to help activate their background knowledge on Motivation at work to be ready for the listening task. The audio was played twice. At the first time listening, the teacher stopped to go around and checked how much the students had completed the task and took note. After that, a second chance of listening is offered.

With the second group, such "preparatory work" was not applied but the teacher repeated the procedure of while-listening activity like group 1.

\section{Results of the tests}

The paper tests of the two groups were collected to check the effectiveness of listening. The teacher marked them to get the final scores for the research.

It should be noticed that in IELTS actual listening test, the recordings were only played once. However, it was possible to have a second time of listening in EFL classroom because the students' current level was inadequate to the real test. In both groups' test, they could listen twice but before repeating, the teacher took notes on how well both of them could do it. Consequently, the final results of the test should be analyzed in line with the students' performance after the first turn of listening.

Survey

Both groups completed the questionnaire with the same multiple-choice items right after they finish their test. There are three main parts to the survey:

The first part includes items about the students' behavior. Wenden (1986) believes that learners' attitude may affect their performance. Therefore, most of the questions are designed to learn about the participants' awareness of listening and the effect of background knowledge on listening comprehension.

The second part asks about learners' habit before listening to know whether they prepare or are instructed to prepare basic steps.

Finally, there are a few questions on learners' suggestions to help them improve IELTS Listening.

In general, the survey is quite simple with multiple-choice questions, which are easy to answer and avoid misunderstanding. This is also a short questionnaire but directly leads the participants to the point about background knowledge in improving listening comprehension. 


\section{Results and Discussion}

In this part, there will be a detailed analysis and evaluation of the data collected, including observing the participants' performance at the test, the test results, and the survey results.

\subsection{Observation}

\subsubsection{Group 1 - with pre-listening activities to activate background knowledge}

The lesson last in 30 minutes, including 15 minutes for pre-tasks, 7 minutes to listen (twice) and the other 8 minutes to figure out the answers and feedback.

In pre-tasks, the teacher introduced the topic "Motivation in the workplace" and Maslow's Hierarchal Needs, respectively. In each section, the teacher had different approaches to provoke students' awareness of the topic. First of all, to mention what motivated people in the workplace, there was a group discussion in 2 minutes in which group members shared what they thought about things that could make people do a better job. After that, the teacher led a whole class brainstorming to get ideas from the students: high salary, good working environment, thoughtful boss, friendly colleagues, promotion opportunities, etc. The teacher then introduced Maslow's Hierarchal Needs with 5 levels of motivation. Before explaining each level, she helped the students understand several new terms: physiological, self-esteem, and self-actualization (vocabulary learning). Because the picture was similar to the note in their coursebook, they were asked to open their books and compare. At each level, the students were encouraged to give examples based on the given information in the task. For example, with Physiological needs, they predicted that there could be: food and drinks, clothes, water, good health, etc. The teacher supported them with other relevant answers. Finally, the students had 2 minutes to read the task and predict the kinds of information needed in each question. By the end of the pre-tasks, the students, in general, could (1) have general information about the topic they are going to listen, (2) predict forms of the questioned words, and (3) predict a few possible answers.

In short, in pre-tasks, some approaches were used to activate students' background knowledge about motivations in Maslow's theory, such as discussion, brainstorming, vocabulary learning, text analyzing, and prediction.

After that, the teacher turned on the audio and the students tried to complete the listening task. They were asked to write their answers in a piece of paper individually. While they were doing their task, the teacher went around and noted their performance.

The teacher then opened the audio file to let the students listen again to complete the missing answers. When the task was done, all the paper was collected.

Finally, the teacher offered the answer, they all listened again to check the key and explain a few terms.

\section{1.2. Group 2 - without pre-listening activities}

The lesson also lasts in 25 minutes, including 7 minutes to listen (twice) and the other 18 minutes to figure out the answers, explaining certain terms from the scripts and feedback.

There is no preparatory step in this group. The students had only 2 minutes to read the text and take note, if any. The teacher let them listen for the first time and asked them to individually write their answers on paper. While they were doing their task, the teacher also went around and noted their performance.

The teacher then opened the audio file to let the students listen again to complete the missing answers. When the task was done, all the paper was collected.

Finally, the teacher offered the answer, they all listened again to check the key and explain a few terms. Because there were no pre-tasks, the teacher spent quite more time in this part to make sure the students understand the answers.

\subsection{Test results}

In the test, the students had to write answers for 5 questions with no more than three words for each. This is a popular task in IELTS listening.

In the first temp listening, the teacher realized that questions 1, 2 and 5 were easy ones with familiar vocabulary. Therefore all of the participants in both groups can complete them right after the first chance: (1) - food; (2) - Security. With the preparation or not, the students could give easy answers. The results showed very little difference in question 1, 2 and 5.

However, in questions 3 and 4, both groups showed different performance. In question 3, almost half of the members in group 1 gave a good answer right at the first time listening: "social-beings" (a few miss plural forms "s" of the word but that kind of 
answer was accepted in this case). Only 3/22 members of this group could complete number 4 simultaneously. The answer for number 4 included two elements, "motivated and successful", so most of them realized only one of the two which is not enough. This showed a better result than those in group 2. Only 3 members gave good answers for number 3 and no one could give a full number 4. They had the same problem with group 1.

Then when the audio was repeated, both groups showed improvement. Three more students could give correct answers for both questions 3 and 4 . At the end of group 1, 12/22 students were correct in question 3 and 17 of them still failed in number 4 . The result was almost similar in group 2, with 11/22 correct answers in question 3 and 5 good responses in question 4.

In conclusion, the results have seen no big differences between 2 groups, except the ability to complete the task in the first time listening. However, this result makes sense because the recording is not repeated the second time in the real IELTS test, so the listeners have to be ready at once. As a result, group 1 might have more advantages than group 2 when they do the real test.

\subsection{Survey}

The results of the survey based on (1) students' attitude toward listening comprehension and IELTS listening; (2) students' behavior in pre-listening and (3) students' suggestions to improve their IELTS listening scores:

\subsubsection{Students' attitude toward listening comprehension}

A language learner might have many problems when doing a listening task such as new vocabulary, a topic that listeners do not have idea knowledge or experience about, speakers' speed, personal anxiety, or failure to concentrate. Chart 1 explains what SGU EFL students encounter when they learn the skill.

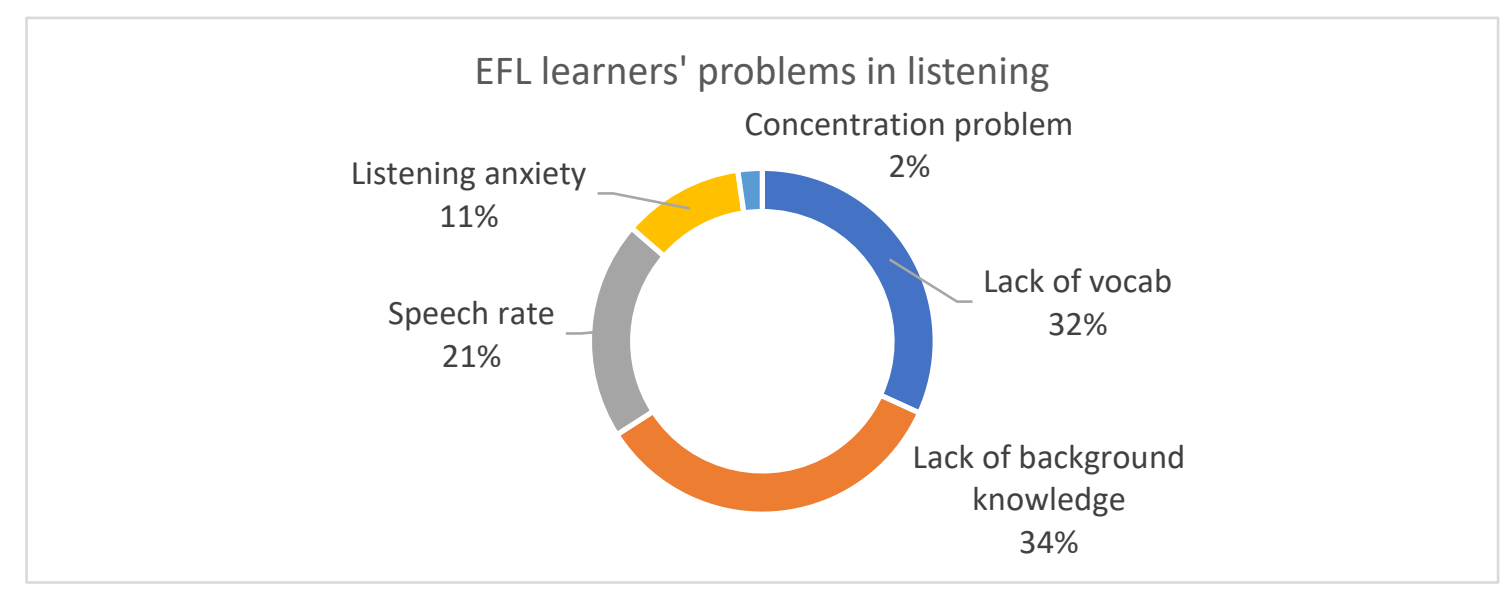

Chart 1 - EFL learners' problems in listening

According to the chart, most of them are less confident with listening skill because they do not have enough vocabulary (32\%), lack prior information (34\%) about the topic they listen or the speed of the speakers (21\%). Those factors refer to linguistic ones (Buck, 2001; Markham \& Latham, 1987). Not many fail to listen just because of anxiety or concentration problems (13\% in total).

Secondly, the research conductor questions the participants on the IELTS Listening (Chart 2). A variety of difficulties in the test are listed, such as difficult vocabulary, high speed and lots of different accents, many questions, many kinds of questions, unfamiliar topics, or the fact that test-taker can only listen once. Those problems make learners find it hard to achieve high scores. Among them, the chart below has shown that the students are most concerned about the topics of IELTS Listening. In fact, 4 sections in IELTS cover topics from academic to non-academic ones, such as history, literature, sports, celebrities, weather, nature and natural disasters, mathematics, physics, science, etc. The second element is vocabulary. The researcher believes there is a great connection between the knowledge learners have in one field and the vocabulary they know about that topic. Therefore, without no doubt, new topics and vocabulary which altogether take charge of $60 \%$ of the choices, are the biggest obstacles to the test-takers.

Moreover, some students are less confident because the recordings are not repeated in the listening test, with limited time to pre-read all the instructions and items, they might miss lots of information that they wish they could have another chance 
listening. Speed and accents are other problems. Only a few students worry about the number of questions also the question types ( $11 \%$ in total).

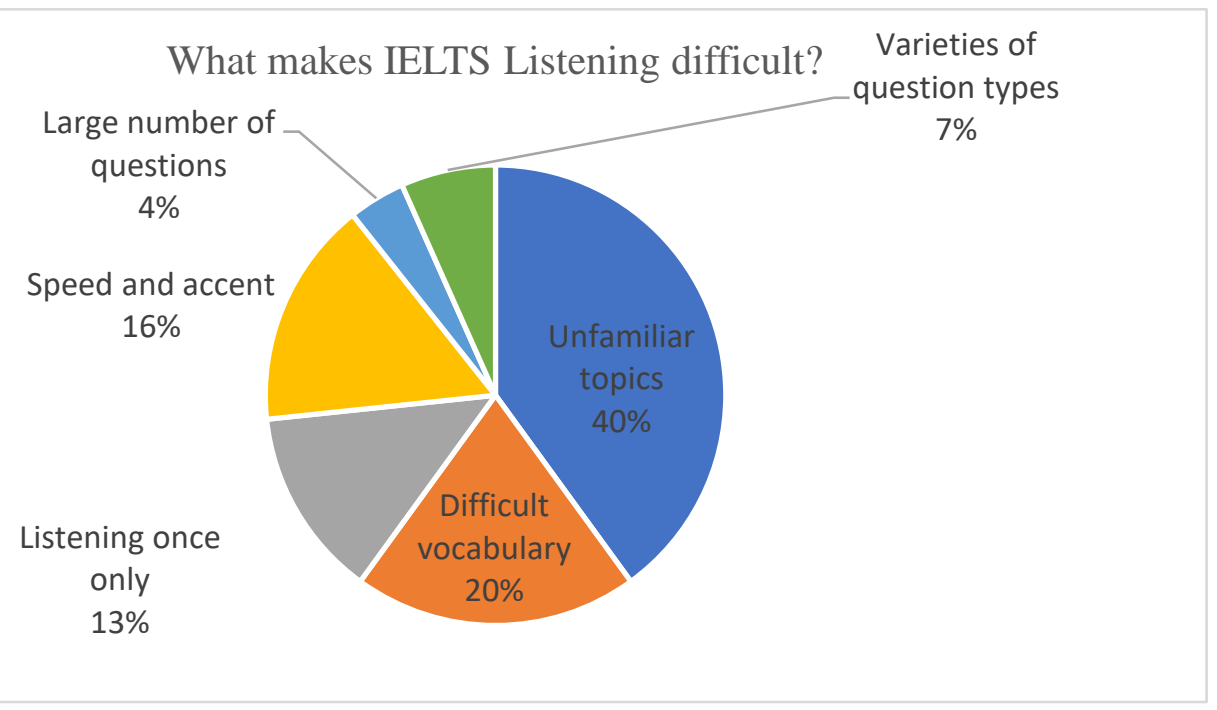

Chart 2 - What makes IELTS Listening difficult?

As mentioned earlier, in the research, the teacher spent the first 11-week supporting students with the same skills and knowledge in the program. That means in each lesson, at least a third of the whole time is used for pre-listening activities. During 11 weeks, the students are familiar with the discussion, brainstorming, explaining keywords or expressions, predicting information, etc. In the next question of the survey, they are asked to tell their opinions about the activities and their roles in listening comprehension. The result is shown in Chart 3. Accordingly, most of the participants agree that pre-tasks are quite important in their listening performance. This opinion is concluded during the time they are conducted how to activate their background knowledge and make use of what they know or may know about a topic to apply in what they will learn. In fact, in Module Listening 3, the students' topics vary from education, history, economics, real estates, nature to finance and banking at a quite high level. Without preparing, learners often find it hard to understand the main ideas of such unfamiliar fields and fail to complete the tasks.

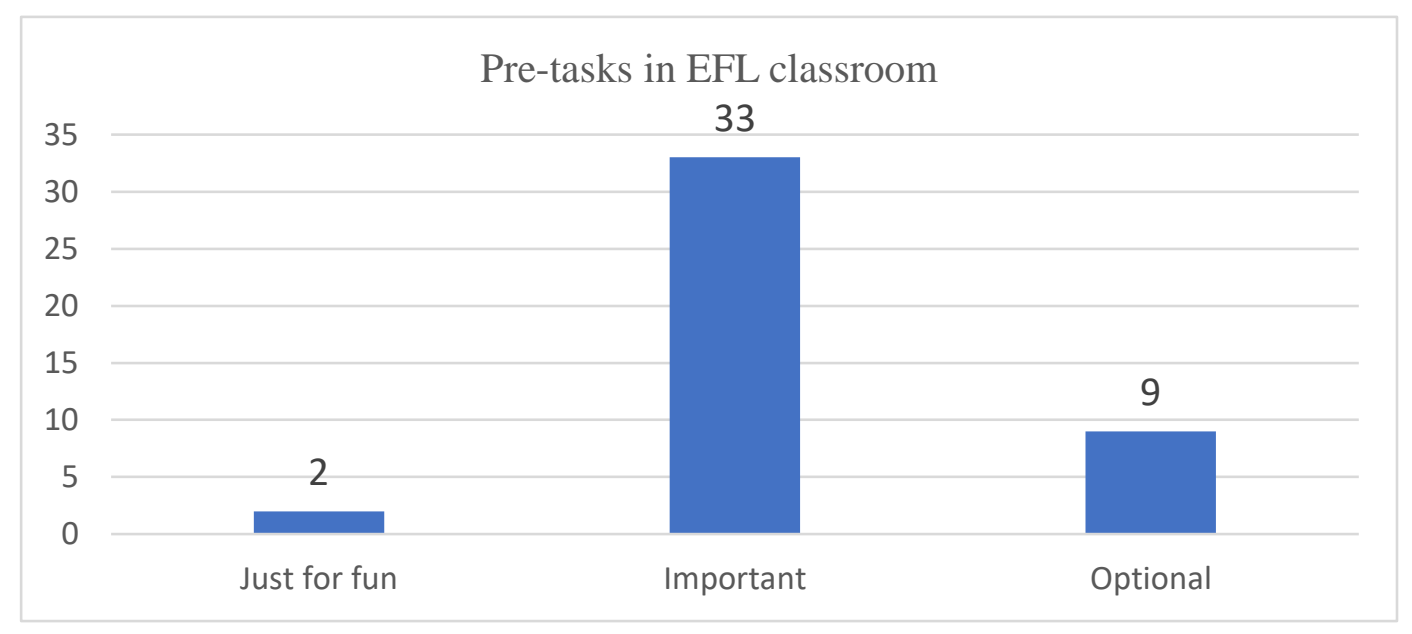

\section{Chart 3 - Pre-tasks in EFL classroom}

In the next item, students evaluate the roles of background knowledge in listening comprehension in details. According to the theories found before, using schemata to activate background knowledge can help learners access the content quickly and interpret new information from listening faster. As a consequence, listeners can do tasks more efficiently. In the survey, most of the participants think that they understand the content more quickly, thanks to pre-tasks (almost half of them). Many other people with the same rate believe from what they already know, they refer to new information and complete the exercises better. Only 4 of them see no improvement. (chart 4) 


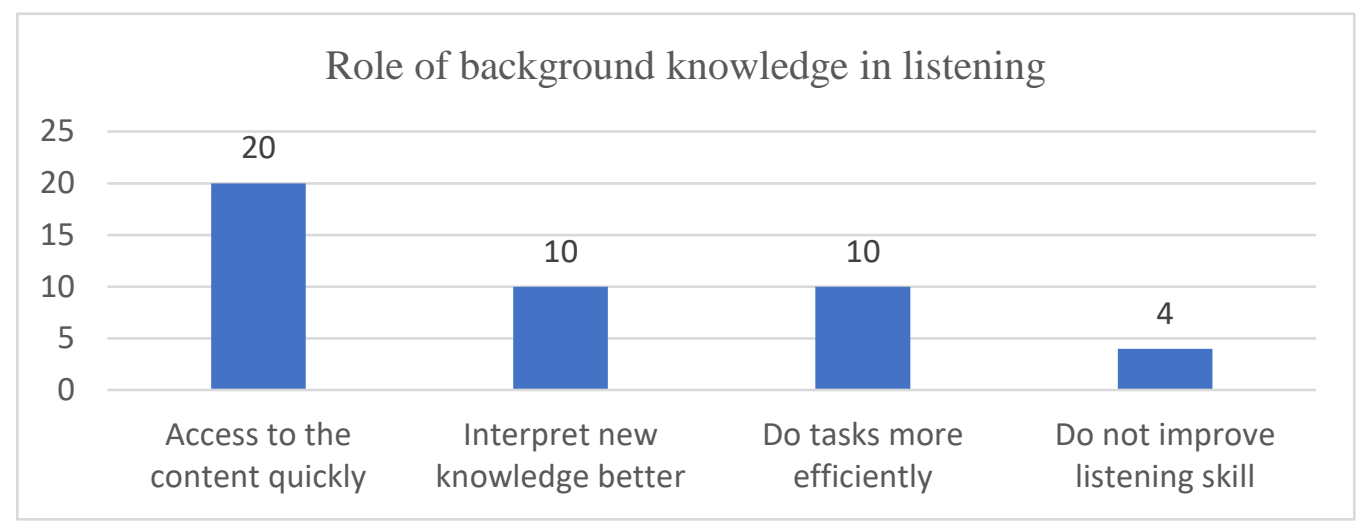

\section{Chart 4 - Role of background knowledge in listening}

In general, the participants have certain difficulties in listening and IELTS listening is a real challenge to them. Activating prior knowledge can be a reliable solution to help improve the skill.

\subsubsection{Students' behavior in pre-listening activities}

During the time conducting the research, every week, the students are required to do many activities to prepare for their listening exercises. However, it does not mean they always like doing that or regularly do that when they self-study. In the second part of the survey, the participants are asked which activities they do as a preparatory step. Chart 5 shows their responses in details. The activities they are likely to use most are reading the instructions and checking up new words which are a must in listening comprehension. In fact, these activities are done by any test-takers. Failure to understand the instructions leads to confusion and failure to answer the questions.

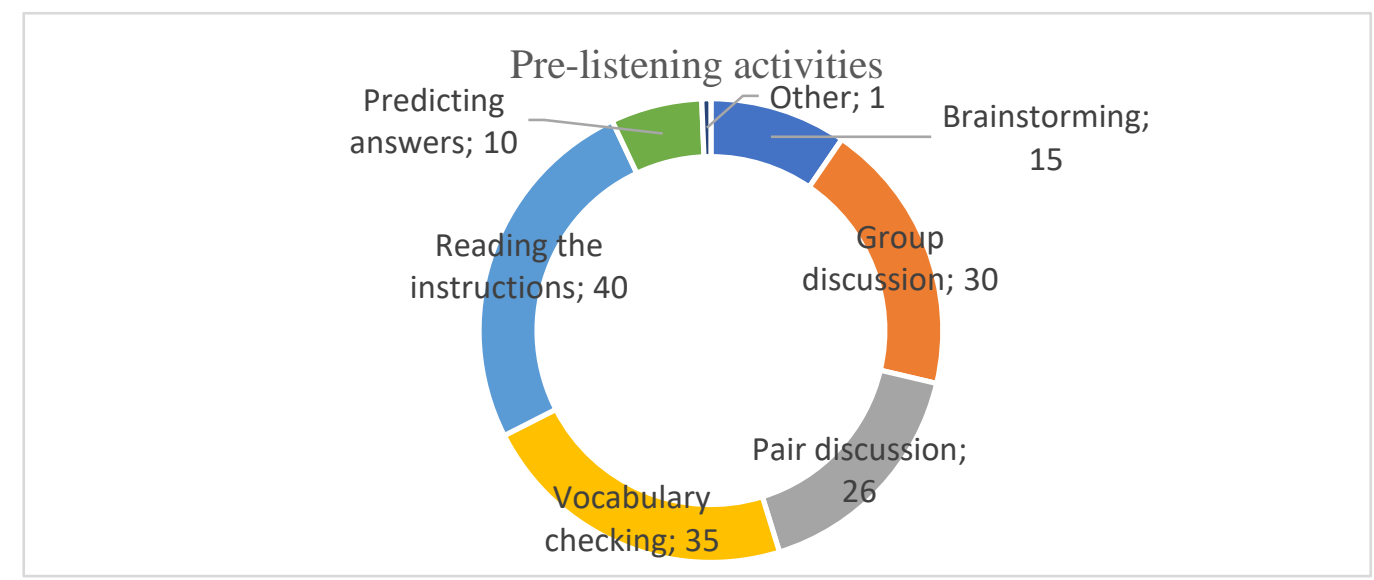

\section{Chart 5 - EFL pre-listening activities}

The discussion, whether in groups or pairs, is also good choices for students. More students prefer working in groups to discuss with a single partner. However, not so many wish to brainstorm ideas on a larger scale. Small groups seem to be most suitable for SGU EFL learners.

One result that surprises the research conductor is that only a few ideas show their preference in predicting which is an essential skill in IELTS. This could be explained that once they focus on background knowledge, they become quite confident with the ideas they have come up with or are supported by teachers; or in fact, they do not have too much time for this activity.

\subsubsection{Students' suggestions}

In the last part of the survey, the participants give their opinions to help improve IELTS listening. 
Chart 6 illustrates their determination in self-practice. As many of them appreciate the role of background knowledge in listening ability shown in earlier charts, 35/44 students say they will do pre-steps even they are practising by themselves at home while 8 people are not sure about their choice. They could feel less motivated doing that without any partners to discuss and share opinions. One rare case that could be one of those who think activating prior knowledge does not help them improve their results refuses to do that.

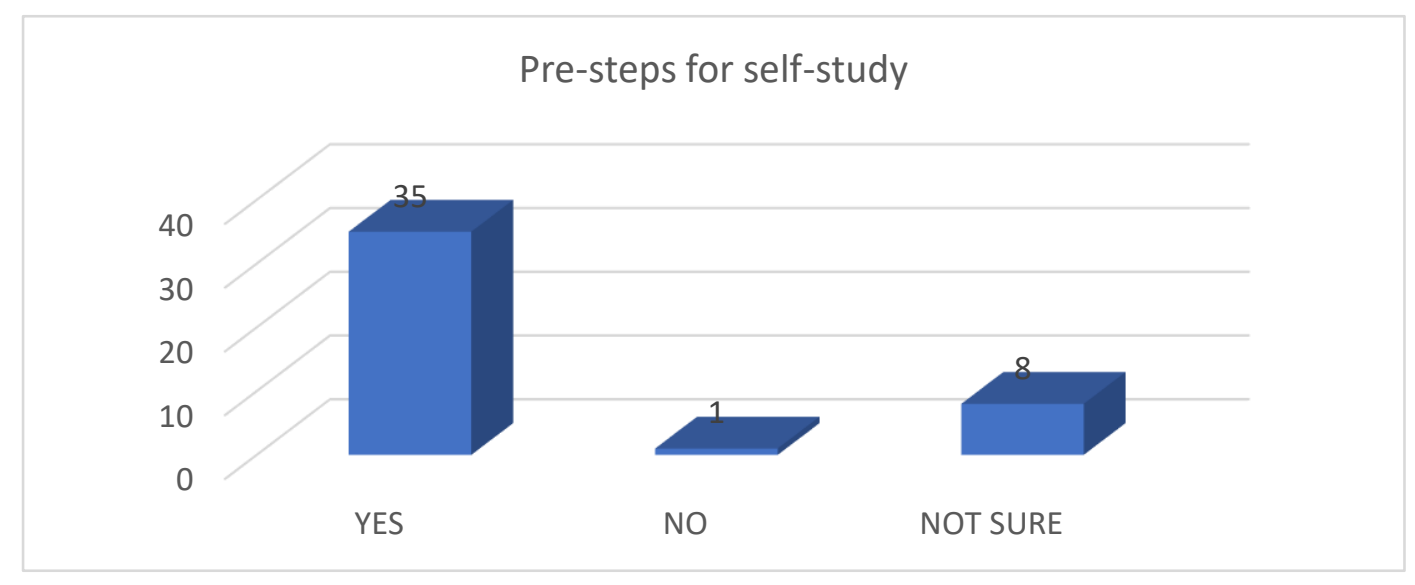

Chart 6 - Pre-steps for self-study

The last item of the questionnaire is an open question. In this question, the students can write whatever they think that can help them improve their listening skill based on activation of their background knowledge. The ideas include:

- Expecting teachers to provide learners valuable information about a variety of IELTS topics.

- Expecting teachers to provide reference materials, both for IELTS Listening practice and background knowledge accumulating.

- Expecting from coursebook: should be updated with new topics. Many think that the current course book was published quite long ago, though providing good techniques shows a few old-fashioned information.

- Having chances to take an IELTS listening test similar to the real one right at SGU.

In general, in this item, the participants are encouraged to write what they need to be done to find it easier to learn new things. The knowledge they can get from the EFL classroom can help achieve their expected IELTS score.

\section{Conclusion}

\subsection{Conclusion of the results}

The research has come up with many results, shown through the class observation in a listening lesson and their recorded test scores, also figures from a questionnaire after completing the test.

\subsubsection{Observation and test results}

Both groups of participants have the same chance to do the test, i.e. the audio is played twice, but before doing the test, the first group is supported with background knowledge in pre-tasks while the other group is not. As a result, the researcher realizes that all of them generally have similar results, in the end, i.e. completing almost 4/5 questions. However, when carefully considering their results at each time listening, there are a bit different: more people in group 1 are able to complete $4 / 5$ questions than in group 2 . The situation only changes when the recording is repeated. Group 2 has improved with more correct answers, while many students in group 1 still fail in question 4 . In the end, comparing 2 results, the researcher can see no big difference between them.

Though test results show a slight difference between 2 groups, it is undeniable that those who well-prepared with background knowledge and pre-listening activities are more confident in the first try. This result points out that IELTS listening is a one-time playing test in reality. If they fail to comprehend what they hear, they have no more chance to do it again. In this case, when listeners are not ready before listening, they could worry and feel less confident about themselves, which greatly affects their real results, especially when they have to encounter a strange topic. As a consequence, it is confirmed that pre-tasks take a considerable role in improving listening performance. 


\subsubsection{Survey}

\section{Students attitude toward listening comprehension and IELTS Listening}

Firstly, they agree that vocabulary and background knowledge are their biggest obstacles in listening. They often experience new words in many fields that make them hard to comprehend a conversation or speech.

The participants have the same opinions about background knowledge. They agree that IELTS covers lots of topics socially and academically, many of which are totally strange and difficult which cause listeners many problems. Therefore, background knowledge plays an important role in improving their listening results by helping them access content easier and interpret new information faster, making them do tasks more efficiently.

This part of the survey has shown that EFL students at Saigon University have a good awareness of listening generally and IELTS Listening particularly. They practice their skills on a regular basis, so they understand exactly what their problems are. During 11 weeks of research, they are provided skills and technique to acquire the question types and accumulate and activate what they really know about the topic to make the best use of it in listening comprehension.

\section{Methods to activate background knowledge}

According to the participants, the most popular activities they do or asked to do to activate prior knowledge in the EFL classroom are: (1) reading the test instructions; (2) pair and small group discussion; and (3) checking for new words.

SGU EFL students neither prefer brainstorming in the big group nor predicting answers from given information.

In fact, those mentioned are popular activities that an IELTS taker may do to prepare for their listening test. However, in this case, it is more suitable for SGU EFL learner to discuss in a small group because of having big size classes (more than 50 students in each Listening Module 3 class that the researcher is teaching). Brainstorming in such big classes makes it difficult for teachers to generalize ideas from students and for students to show their best.

\section{Students' suggestions to improve listening results}

In this part, the students show their willingness to self-practice listening with pre-steps. On the other hand, they write a few more suggestions and expectation in order to help them improve their performance. Most of their opinions refer to sources of materials that teachers can provide and updated materials they can learn in class.

\subsection{Recommendation}

The paper is conducted in order to emphasize the role of preparation work in listening comprehension. Therefore, from what has been done, there are the following suggestions for both students and teachers in EFL classroom:

\subsubsection{Students}

Students should mainly be responsible for their IELTS scores; therefore, they should show much effort. In the research, most of the students are aware of the role of pre-tasks in listening comprehension and understand how they could be useful in doing listening activities. Here are several recommendations for EFL learners:

\section{Learning in class}

Classroom activities are varied and important as they encourage interactions among learners. As a consequence, via pair or group discussion, brainstorming, questions and answers or task completion activities instructed by the teachers, students can either expand social and academic knowledge thanks to both teachers and classmates. Students, therefore, should pay more attention to preparatory activities in class rather than checking for words meaning or tapescript.

Lectures from teachers are also good sources of knowledge. In this case, an active learning style is encouraged, i.e. students are welcome to give opinions and raise questions whenever necessary to build up the lesson and train thinking critically.

\section{Self-study}

Self-practice predicting skill

Predicting is an important skill in IELTS, mainly shown in pre-steps. When students study in their classroom, they are likely to discuss and work in small groups with support from teachers and classmates. However, these activities are not suitable when they exercise at home alone, outside their official class. In this case, predicting skill becomes powerful. In fact, predicting can help listeners be ready for their tasks and in case when they fail to figure out an answer, sometimes this step can help save a point for 
the test-takers. Therefore, it is advisable that students read the questions and predict the types of information they need to answer, the kinds of words to complete or try writing down the items without listening.

\section{Accumulating background knowledge}

It is not always easy to know a lot about a particular topic without reading and learning about it. IELTS is an international test that requires its test-takers to have good skills and wide knowledge socially and academically. In order to achieve the best scores, students are expected to work hard both in the EFL classroom and at home. While in class, students are often instructed with skills, vocabulary and knowledge by their teachers. Students may feel less motivated to work by themselves at home. Therefore, it is encouraged that they follow pre-listening activities as learnt in class. Learners may find it easy to prepare vocabulary and predicting activities; however, they could fail to explain a few expressions or information due to a lack of prior knowledge. In a nutshell, they are advised to enrich their knowledge by reading different sources of materials, either in familiar or unfamiliar fields, available online or in books.

\subsubsection{Teachers}

To be confirmed that background knowledge plays an important role in listening comprehension, EFL teachers are recommended to (1) instruct students to do preparatory activities that help expand their knowledge on the topics, (2) guide them on how to relate what they already know about a topic with tasks to complete, and (3) offer them good sources of materials to practice both skills and knowledge that are popular in IELTS.

As a teacher, the research conductor understands that teachers take an important role in supporting students with proper skills and knowledge. During the whole semester of conducting the research, the participants and their classmates are directed to prelistening activities, with the hope that they build up a habit of analyzing and thinking critically before doing the test in order to perform better in their real test

Teachers are always the ones that encourage, support and guide students on the way to achieving their expected results.

\section{References}

[1] A. H. Omaggio (Ed.), Research in language learning: Principles, processes, and prospects (pp.124-155). Lincolnwood, IL: National Textbook.

[2] Arif, S. \&. (2016). The Use of Task-Based Activities to Improve Listening and Speaking Skills in EFL Context. Sino-US English Teaching Vol. 13, No. $6,445-459$.

[3] Badger, Yan, X. (2009). The use of tactics and strategies by Chinese students in the Listening Component of IELTS. IELTS Research Reports, 9 , 67-96.

[4] Bartlett, F. C. (1932). Remembering: A Study in experimental and social psychology. Cambridge: Cambridge University Press.

[5] Brown, G, \& Yule, G. (1983). Discourse analysis. Cambridge: Cambridge University Press.

[6] Brown, S. (2006). Teaching Listening. New York: Cambridge University Press.

[7] Carrel, P. L., \& Eisterhold, J. C. (1983). Schema theory and ESL reading pedagogy. TESOL Quarterly, 17(4), 553-573.

[8] Kurita, T. (2012). Issues in second language listening comprehension and the pedagogical implications. Accents Asia, 5(1), 30-44.

[9] Field, J. (2009). The Cognitive Validity of the Lecture-based Question in the IELTS Listening Paper. IELTS Research Reports, 9, $17-65$.

[10] Goh, C. (2000). A cognitive perspective on language learners' listening comprehension problems. System, 28(1), 55-75.

[11] IELTS 10. (2015). Examination papers from University of Cambridge ESOL examinations. Cambridge: Cambridge University of Press. (4 $\mathrm{x}$ Listening tests).

[12] Liu, H. J. (2008). A Study of The Interrelationship Between Listening Strategy use, Listening Proficiency Levels, and Learning Style. RARECLS, 5, 84-104.

[13] Nunan, D. (2004). Task-based language teaching. Cambridge, . UK: Cambridge University Press.

[14] Oxford, R. (1993). Research update on teaching L2 listening. System, Vol.21, No.2, Pp: 205-211

[15] Richards, J. C., \& Schmidt, R. (2010). Dictionary of language teaching \& applied

[16] linguistics. London: Pearson Edition.

[17] Rost, M. (2002). Teaching and researching listening. London, UK: Longman.

[18] Swaffar, J. K., \& Bacon, S. M. (1993). Reading and listening comprehension: Perspectives on research and implications for practice.

[19] Underwood, M., \& Kenworthy, J. (1989). Teaching listening. M. Rost (Ed.). London: Longman

[20] Underwood, M. (1989). Teaching listening. Hong Kong: Longman.

[21] Williams, E. (1987). Classroom reading through activating content-based schemata. Reading in a Foreign Language, 4, 1-7.

[22] Young, D. J. (1999). Affect in Foreign Language and Second Language Learning: A Practical Guide to Creating A Low-Anxiety Classroom Atmostphere. (Ed.). USA: Mc-Graw-Hill Company. 